\title{
CONTRACTUAL REGISTRATION OF ORGANIZATIONAL AND LEGAL RELATIONS BETWEEN SUBJECTS INVOLVED IN THE CONDUCT OF CLINICAL TRIALS OF MEDICINAL PRODUCTS
}

DOI: 10.36740/WLek202012223

\author{
Olena I. Antoniuk', Yuliia M. Pavliuchenko², Ivan I. Vyshnyvetskyy ${ }^{3}$ \\ ${ }^{1}$ SUPREME COURT, KYIV, UKRAINE, UKRAINIAN ASSOCIATION FOR CLINICAL RESEARCH, KYIV, UKRAINE \\ VASYL' STUS DONETSK NATIONAL UNIVERSITY, VINNYTSIA, UKRAINE \\ ${ }^{3}$ BOGOMOLETS NATIONAL MEDICAL UNIVERSITY, UKRAINIAN ASSOCIATION FOR CLINICAL RESEARCH, KYIV, UKRAINE
}

\begin{abstract}
The aim: Determination of features of contractual registration of organizational and legal relations between the subjects involved in carrying out clinical trials of medicinal products; justification of proposals on improvement of law enforcement practice in this field.

Materials and methods: This research is based on the analysis of the norms of international law and legislation of particular states, practice of contractual registration of organizational and legal relations between the subjects of clinical trials of medicinal products. The research was carried out using the methods of dialectical and formal logic, general scientific and special legal research methods.

Conclusions: Two models of contractual registration of organizational and legal relations between the subjects involved in clinical trials of medicinal products were justified, and law enforcement recommendations for the contractual registration of such relationships, ensuring that the clinical trial is in compliance with international regulations and ethics in this field, were given.
\end{abstract}

KEY WORDS: sponsor, hospital, CRO, SM0, researcher

Wiad Lek. 2020;73(12 p. II):2840-2847

\section{INTRODUCTION}

The issue of regulatory support for clinical trials of medicinal products (hereinafter -clinical trials) is becoming increasingly important given the significant societal threats that have recently emerged in healthcare. The announcement by the World Health Organization of the COVID-19 pandemic due to the outbreak of the new SARS-CoV-2 virus has affected the area of clinical trials - a need for additional standardization of vaccine testing for this disease (at the legislative level), as well as organizational changes in testing other medicinal products (at the local level, in particular, in standard operating procedures, orders for the organization of clinical trials in a pandemic and quarantine), has been raised. Besides, relevant orders and guidelines are developed by national regulators, such as the FDA Guidance on Conduct of Clinical Trials of Medical Products during COVID-19 Public Health Emergency [1].

The epidemic situation and the restrictions imposed by the states create additional difficulties in the implementation of the trial protocol, in strict adherence to the schedule of visits, procedures and surveys, which creates additional risks for the reliability of the data obtained during the trials. Customers and performers of clinical trials face additional organizational issues due to the need to ensure maximum protection of study subjects and the research team, as well as to minimize the impact on the integrity of clinical trial data.
Proper organization of the trial protocol execution process, first of all, is ensured by the proper construction of relations between the various subjects involved in the conduct of clinical trials, and their appropriate contractual registration. There is no coincidence that the contractual registration of the relations of the subjects involved in the conduct of clinical trials is one of the preconditions for their realization.

The issue of contractual registration of organizational and legal relations between the subjects involved in clinical trials is underresearched in scientific literature, however these issues require proper scientific investigation.

\section{THE AIM}

The purpose of the research is to determine the features of the contractual registration of organizational and legal relations between the subjects involved in the clinical trials, substantiation of proposals to improve law enforcement practice on the issue.

\section{MATERIALS AND METHODS}

To achieve the objectives of the research, statistical data on the number of clinical trials worldwide were analyzed, global and local trends in the field of such trials were considered. 
The peculiarities of normative regulation of organizational and legal relations between the subjects involved in conducting clinical trials in different states were analyzed, including the international normative acts, as well as normative acts of particular states on the subject of research, the agreements on conducting clinical trials and provision of services related to their implementation, in particular, more than a hundred of agreements between foreign sponsors and Ukrainian performers of clinical trials were analyzed.

The methods of theoretical analysis and synthesis were used in the research during the study of the content of legal norms and concepts contained in regulations and ethical norms. The method of system analysis was used to differentiate the functions of subjects involved in clinical trials. Formal and legal analysis of regulatory requirements on organizational and legal relations between subjects involved in clinical trials create possibility to reveal disadvantages in law enforcement practice and to formulate proposals to avoid them by delimiting the functions of these subjects.

The comparative method was used in the analysis of the peculiarities of regulation of organizational and legal relations between the subjects involved in clinical trials in different countries. In solving the research problems other methods have been used, such as formal-logical (to identify differences between the subjects of contracts made with different subjects involved in clinical trials), functional (in establishing the impact of the legal status of the subject on the content of services provided), sociological (when identifying factors affecting the dynamics of the number of registered clinical trials) and some others.

\section{REVIEW AND DISCUSSION}

Statistics data show that the number of clinical trials is growing differently in different regions. For example, in the regions of Europe, North and South America and the western part of the Pacific Ocean, it has recently grown much faster than in other areas of the world. Thus, in 2019 the number of registered researches in the western Pacific $(16,675)$ was 23 times higher than the number of trials in Africa (716). Since 2016 the West Pacific region became the region with the largest number of registered trials per year due to the registration of a large number of trials in the People's Republic of China (hereinafter - the PRC) and Japan. Also, the number of registered new surveys is growing much faster in high-income countries. For example, in 2019 the number of registered surveys in high-income countries $(27,461)$ was 84 times higher than the number of surveys in low-income countries (326) [2].

In Ukraine for the period from 1999 to 2019, 4,203 clinical trials were registered, which is $2.57 \%$ of the total number of trials registered during this time in Europe. For example, in the Republic of Turkey - 7,008 trials, in the Republic of Poland - 12,072, in the Islamic Republic of Iran - 22,897, in the Italian Republic - 23,097, in Canada $-27,185$, in the Republic of India - 27,638, in the Federal Republic of Germany (hereinafter - Germany) - 39,580, in the PRC - 46,149, in Japan - 45,856, in the United States of America - 134,516 [2].
Legislation in the field of clinical trials is represented by the international acts, besides, by EU acts, and also by the national legislation of each state. The stage of development of each particular state's legislation was actively studied, including compliance with EU acts respectively [3-5].

The legislation regulates mainly public-law relations concerning clinical trials (in particular, the procedure for their state registration, assessment of moral, ethical and legal aspects, monitoring, etc.), and the contract is a regulator of private-law relations arising between the customer of the clinical trial (hereinafter - the sponsor) and its executors and other subjects involved in its realization (determines, in particular, the rights and obligations of the parties, the procedure and amount of payment for relevant services and works, conditions for ensuring the confidentiality of research data, protection of personal data and rights to intellectual property used or created as a result of testing, issue of storage of research documentation, use of its materials, interaction with regulatory authorities and other people involved in its implementation).

The clinical trial is preceded by a stage of contractual registration of relations with the subjects involved in its execution, in particular, with the contract research organizations (further - CRO), its executors (in particular, research centers - health care institutions, scientific institutions, medical universities and also researchers, co-researchers, research coordinators, laboratories), science center management organizations (hereinafter - SMO).

When conducting clinical trials, the sponsor often uses an intermediary model of relationships with other trial participants, involving the $\mathrm{CRO}$, which deals with pre-contractual and contractual work with performers and other trial participants. According to paragraph 1.20, the ICH GCP CRO is the organization to which the sponsor officially delegates one or more of its responsibilities and functions for conducting a clinical trial [6].

If in the early 1970s there were about 50 CRO in the world, in 1980 there were 150, in the mid-90s of the 20th century there were 1,500 and now there are about 2,500 of them worldwide, among which 500 are in the United States, 200 in the United Kingdom, 150 in France, 100 in Germany. Today, CRO has become an important element of the clinical trial system. For example, most Japanese pharmaceutical companies conduct clinical trials abroad only through CRO [7, p. 118, 119].

At the same time, some researchers claim that CROs complicate the process of negotiating contracts with the subjects of the research [8, p. 549].

The most common model of building organizational and legal relations between the subjects involved in clinical trials is the sponsor' ordering (CRO on behalf of the sponsor) to complete the clinical trial in the health care institution (hereinafter - the hospital), which conducts such research.

Normative regulations on the organization of clinical trials in different countries have otherness that affects the contractual registration of such legal relations.

For example, in the Republic of Finland, such a contract sets out the rights and responsibilities of the researcher as 


\section{Sponsor (CRO)}

Fig. 1. Model of linear relations of clinical trials participants.

a hospital employee. The British legislation stipulates that the researcher is an employee of the institution responsible for the organization and payment of his work, and if the researcher is not an employee of the institution, this institution undertakes to determine the issue of payment with its direct employer [9, p. 149].

Therefore, in the latter case, the executor of the clinical trial (hospital) independently involves, if necessary, another organization, whose employees will be researchers, while remaining responsible to the sponsor for the implementation of the contract. Such a model of organizational and legal relations of the participants of the clinical trial can be conditionally named the model of linear relations (Fig. 1).

The second model of organizational and legal relations between the subjects involved in clinical trials (it is common, in particular, in Ukraine and some other post-Soviet countries), can be provisionally named as model of parallel relations (Fig. 2), is characterized by making a contract with (by the sponsor (CRO)) :

1) a hospital in which the place of the trial conduct is determined (hereinafter - PCT), as well as a higher medical educational institution (hereinafter-HMEI) or a scientific institution (hereinafter - SI), if they are involved in the clinical trial;

2) researcher, co-researchers, trial coordinator, institutions involved in laboratory and (or) diagnostic tests that cannot be performed in the hospital.

Thus, the peculiarity of this model of contractual regulation of organizational and legal relations in the field of clinical trials is that in case of need to involve other (then hospital) person to perform a clinical trial or provide related support services, the sponsor enters into particular contracts with such subjects.

In Ukraine the first model is used in private hospitals, and the second one is used in state and municipal hospitals, which is explained by the peculiarities of the legal regime of state and communal property, the legal personality of such hospitals for entering into contracts and regulatory requirements on giving wages to their employees.

The possibility of entering into a contract with a researcher by the sponsor is provided, for example, in the Rules of Good Clinical Practice of the Eurasian Union 2016, which states: financial issues of the study should be reflected in the contract between the sponsor and the researcher (medical institution) (subparagraph 4.9.6 and paragraph 5.9.); entering into a contract between the sponsor and the researcher (medical institution) or any other part participating in the clinical trial (subparagraph 5.1.4.), in particular, between the sponsor and the CRO, and if necessary - between the researcher (medical institution) and the relevant authority (subparagraph 8.2.6) [10]. Similar norms are contained in the National Standard of the Russian Federation "Appropriate Clinical Practice" [11].

The organization of a clinical trial in the second model may be accompanied by entering into a contract on:

1. conducting a clinical trial: between a sponsor (CRO) and a hospital (where the PCT is defined) or between a sponsor (CRO), a hospital and HMEI or SI, if they are involved in conducting a clinical trial on a hospital basis;

2. the provision of additional services and (or) the performance of work related to clinical trials between the sponsor (CRO) and the researcher and (or) other subjects involved in the clinical trial (in particular, with the trial coordinator);

3. provision of laboratory or medical diagnostic services (eg. computer tomography) by the sponsor (CRO), if such services cannot be provided by the hospital where the PCT is defined. In the first model, such contract is not made by the sponsor, but by the hospital;

4. cooperation between the hospital and HMEI or SI, if the clinical study involves a researcher - an employee of the department of HMEI or SI, which do not have their own clinical base;

5. cooperation between the hospital and the researcher, other subjects involved in the clinical trial, provided that the sponsor (CRO) makes a contract with such persons for the provision of services and (or) performance of work related to the trial.

It should be noted that the subjects of the contract made by the sponsor (CRO) with different entities are different.

The subject of the sponsor's contract (CRO) with the hospital (HMEI or SI) is the implementation of clinical trials. The hospital provides these services with the help of its available material and technical base and its employees (doctors, other medical staff).

In this case, the researcher does not have the status of a contract party (hospital holds this status), and performs actions as a hospital employee. The relationship between the hospital and the researcher is regulated by labor legislation. Ukrainian legislation stipulates that the hospital conducts the main activities of clinical trials (patients treatment, observation, etc.), as it defines the PCT [12].

Therefore, the sponsor's contract (CRO) with the hospital cannot be considered as an agreement on the use of only material and technical resources of this institution. The hospital is a participant, that is an entity that conducts a clinical trial (but not the area of its conduction, a set of buildings, equipment and facilities).

So, the conduct of clinical trial protocol procedures related to medical decision-making should be specified in 


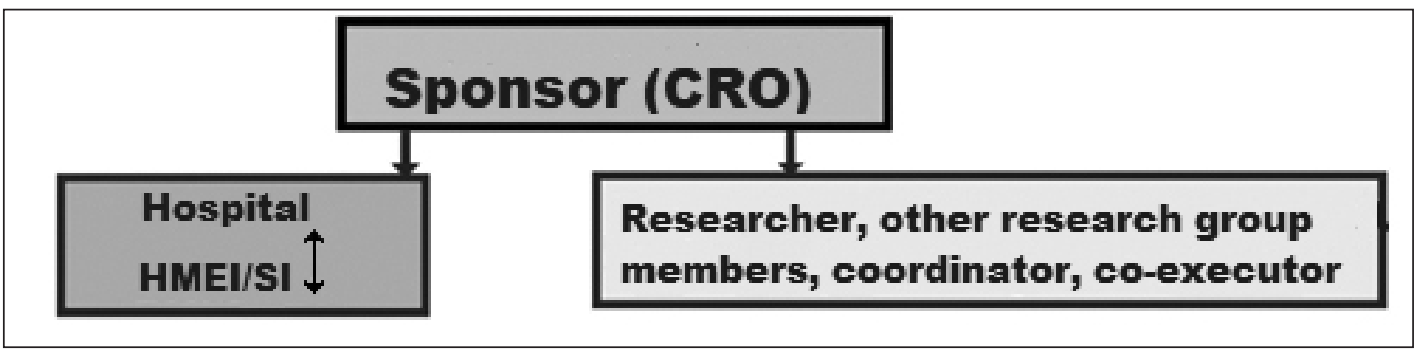

Fig. 2. Model of parallel relations of clinical trials participants

the contract with the hospital, and if the latter is not able to conduct a specific diagnostic or laboratory research, in the contract with other institutions involved in providing relevant services (work implementation).

The contract with the researcher, as well as with other subjects involved in clinical trials, includes those works (services) that are additional (to the "medical part" of the clinical trial protocol) and, mainly, intellectual and organizational by the nature.

Entering into the particular contract with a researcher (another member of the research team) occurs when, within a clinical trial, he is assigned responsibilities that he does not perform within his duties in the hospital during working hours. This occurs because the relevant work or service is not covered by the doctor's job function in the hospital, or because the contract, made by the sponsor (CRO) with the hospital, does not provide relevant work or service.

Based on a separate contract, the sponsor (CRO) may order information from the researcher, in particular, consulting services, information and methodological support for clinical trials, services for organizing the trial process and (or) the process of attracting subjects, creating intellectual property objects, management, supervision and coordinating the research team, supporting the monitoring and audit of testing, generating, quality assurance, collecting, processing, compiling and transmitting research data to its sponsor.

Works (services) ordered by the sponsor (CRO) from the researcher are paid for in favor of the latter. For the work performed by the researcher during the working hours in the hospital, the funds are received by the hospital, which personally decides on the payment of its employee.

Analysis of the content of a large number of agreements concluded between these persons within the second model of contractual relations of clinical trial participants in Ukraine, shows a mostly formal approach to determining the terms of these agreements, which leads to similarity (sometimes identity) of the content of agreements between the sponsor (CRO) and the hospital with the content of the agreements between the sponsor (CRO) and the researchers (co-researchers, coordinators) and the lack of specification of the responsibilities of the hospital and the researcher as separate participants of the clinical trial.

This is partly because it is based mainly on agreements developed in other countries (using the first model of contractual regulation of relevant relations), which try to formally adapt to the legislation of the PCT. Usually, it leads to the use of legal constructions that do not comply with the PCT legislation. Similar draft contracts are tried to be used in the registration of contractual relations with the researcher (co-researchers) for additional services (works), often replacing only the hospital data with the data of the researcher (co-researcher). It is common to specify in the draft contract that the researcher is given the responsibilities of the hospital, and in the contracts with the hospital that is given the responsibilities of the researcher as its employee, and not the hospital as a party to the contract.

Incorrect or unclear definition of the subject and other contract terms between subjects involved in the clinical trial reduces the effectiveness of its conduction; depersonalizes responsibility for conducting clinical trials; raises issues about the fairness of payment for the services of the hospital and the researcher; can affect researchers' income taxation.

The agreement with the researcher may contain terms for the sponsor's (CRO) reimbursement of the latter's costs for the patient's participation in the clinical trial (in particular, reimbursement of transportation costs for the visits to the hospital).

There are two options for payment of the compensation:

1) the researcher spends his own money to cover the patient's transportation costs. In this case, the sponsor (CRO) does reimburse the researcher for the money spent. The payment of such compensation is usually related to the researcher's invoices, which indicate the amount of money spent and the impersonal data of the patients whom such compensation was paid out;

2) the sponsor (CRO) allocates funds in advance to cover the transport costs of patients, transferring them to the researcher, who transfers these funds to patients. In practice, such costs are not separated from the payment received by the researcher from the sponsor (CRO). EU regulations allow compensation for costs incurred by research subjects in connection with participation in the trial [13, p. 189].

In the EU these issues are covered by Regulation (EU) №536 / 2014 [14], which prohibits the provision of material reward or financial incentives (other than compensation) for minors and incapacitated persons. The Regulation (EU) provides the possibility to pay compensation not only for damage to their life or health, but also for costs incurred in connection with the trial for vulnerable research groups of subjects.

Organization of compensation of expenses of subjects for participation in a clinical trial is a service of the spon- 


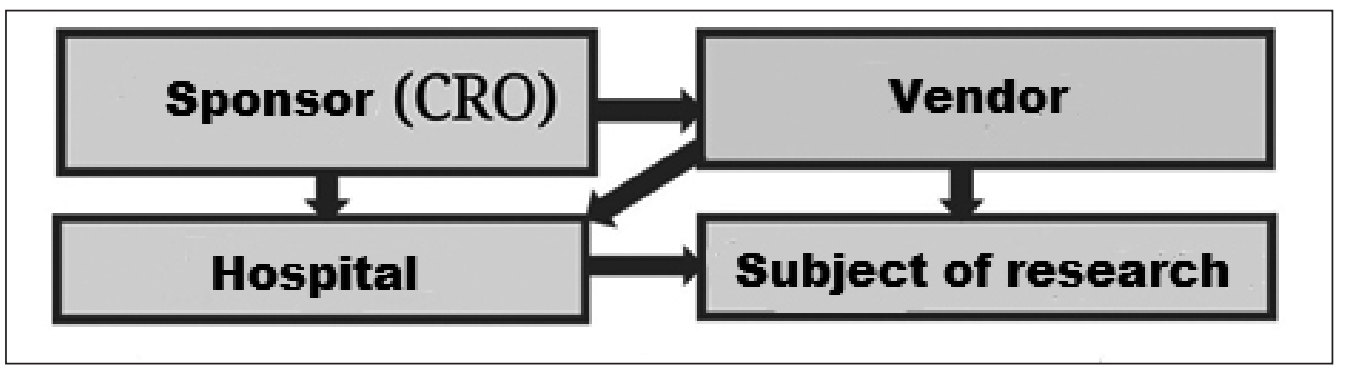

Fig. 3. Organizational and legal relations between participants of the relationship on payment of the research subject's participation in the clinical trial

sor's researcher, provided at the expense of the latter, and the funds provided in the contract with the researcher as reimbursement of patients' visits are not paid for services (works) of the researcher. They may be considered by the researcher's costs related to the services provided to him if the latter include the organization of such visits.

Payments of compensation and (or) rewards to research subjects for participation in a clinical trial should be mentioned in contracts with the researcher or with other subjects that provide services for organizational support of such payments to patients if such payments are agreed upon in the prescribed manner.

The relationship between the hospital and the researcher (co-researcher, coordinator) as a separate entity involved in conducting a clinical trial on the basis of the hospital, regardless of whether he is a hospital employee (HMEI or SI), may be regulated in the cooperation agreement with the hospital. It is also advisable to regulate the interaction of such subjects during the provision of services (implementation of work) related to the trial in the sponsor's contract (CRO) with the hospital to conduct the trial.

If during the clinical trial there is a need to involve staff to perform work (services) not related to medical decision-making (coordination and logistics of patient visits to the hospital, accounting for trial materials and investigational medicinal products, technical support and providing some research procedures, filling out individual registration forms, cooperating with the hospital ethics commission, maintaining a quality control system, preparing reports, ensuring proper paperwork, etc.), research coordinators, data entry specialists, quality specialists, pharmacists may be involved in their implementation.

Thus, it is common in the world practice of conducting clinical trials to appoint a researcher in the PCT Study Coordinator, Clinical Research Coordinator, who is a specially trained person who will assist the researcher in organizing the clinical trial, besides, will deal with the logistics of research materials, laboratories, visits subjects of research, control over the maintenance of primary medical records, filling out individual registration forms. The responsible researcher may delegate his / her responsibilities to the Study Coordinator, except for medical decisions and general control over the implementation of the study in the PCT [15].

If specified duties are not included in the scope of responsibilities of the hospital (HMEI, SI), defined in the contract for the clinical trial, the sponsor (CRO) or the researcher in agreement with the sponsor (CRO) enters into a separate contract with the coordinator for relevant services (work), because the participation of the coordinator cannot be provided in this case by delegation - the researcher cannot delegate more powers than he has.

Also, during the clinical trial a co-researcher doctor or nurse (for laboratory and analytical work in the local laboratory, preparation of tests for the central laboratory, etc.), pharmacist (for acceptance, registration, accounting, preparation, issuance to the researcher of the study medicinal product, temperature register, maintaining documentation related to the medicinal product), narrow specialists (radiologist, bacteriologist, endoscopist, infectious disease specialist, ultrasound diagnostician, neurologist, etc.) may be involved [16, p. 24-25]. If their activities are covered by a hospital contract with a sponsor, the sponsor (CRO) does not enter into separate agreements with them.

In general, the list of persons who can be involved in a clinical trial is not legally limited, the range of these persons and their responsibilities are determined by the sponsor (CRO), or in each particular trial, taking into account the protocol and design of the trial, and also the number of subjects under this trial.

The second model of organizational and legal relations in conducting clinical trials, is characterized by the entering into contracts by the sponsor with both the hospital and the researcher, other persons who provide services (perform work) related to clinical trials that are additional to the hospital services, is strictly prohibited in the legislation of some states. For example, in the UK, some financial arrangements between the sponsor (CRO) and any other hospital unit (including pharmacies) or the university where the researcher works are prohibited (financial issues must be settled between the hospital and the relevant entities) [9, p. 149-150].

In world practice, the involvement of SMO into clinical trials is widespread.

It should be noted that:

1) The SMO may be involved by both the sponsor (CRO) and the hospital, and its functions (rights, responsibilities) in conducting the clinical trial are defined in the contract.

The SMO can perform auxiliary functions (choosing a hospital for a specific clinical trial and coordinating its work, finding patients, technical support, control and risk management, staff training, logistics of clinical trial procedures, organization of transportation services, etc.) that 
improve trial management and administration positively influencing its holding [9, p. 160].

The SMO may perform technical work and provide other non-clinical analytical, consulting services necessary to ensure the clinical trial, in particular: interact with the ethics committee, translate, copy, prepare documents and other specialized auxiliary office activities; coordination, organization and control over the maintenance of clinical trial documentation; control over the completeness and timeliness of providing the customer with a trial of reporting information; organization (if necessary) of involvement of independent consultants on technical issues (in particular, to ensure the operation of medical equipment used during the study, if the relevant specialists are not in the hospital).

2) $\mathrm{SMO}$ is a different organization from CRO. If, despite its name, $\mathrm{SMO}$, such an organization actually performs the functions and powers of the $\mathrm{CRO}$, it will be subject to the requirements of the legislation on the CRO [17].

The nature of the services (works) ordered by the sponsor (CRO) in SMO may determine the need to conclude a contract with the hospital (researcher) or to regulate the procedure of its interaction with the hospital (researcher) in the sponsor's contract (CRO) with the hospital (researcher).

The organization of payment for the benefit of research subjects of certain funds, if it agreed in the manner prescribed by law, may be an independent subject of the contract made by the sponsor (CRO) with the vendor, which undertakes obligations to organize and conduct on behalf of and for sponsor account these payments. The subject of such agreement is services for the organization and payment of compensation in favor of the subject in connection with his participation in a clinical trial.

Implementation of such an agreement requires entering into contract with the subject of the research, which may be called a "contract for the provision of services related to the patient's participation in a clinical trial." The subject of the research does not provide services under this agreement to the specified vendor. Such a vendor acts as an agent (representative) of the sponsor based on a contract for the provision of services for the organization of the relevant payment (Fig. 3). The data obtained from the results of the research are not transferred to this vendor, it is the sponsor's property and its transfer to the latter is regulated in the sponsor's (CRO) agreements with the hospital and (or) with the researcher.

It should be noted that the agreement between the vendor and the subject does not oblige the latter to participate in the clinical trial. The reference to the fact that the subject of the trial, having given informed consent to participate in the clinical trial, has agreed to participate in it, is used in such an agreement only to indicate the condition of its conclusion and does not violate the right of this subject to terminate at any time in this trial and is not coercion to such participation.

Polar provisions are expressed regarding the payment of the research subject's participation in the clinical trial, namely:1) such payment may reduce the participant's understanding or the voluntariness of his informed consent;
2) the absence of such payment may be unethical, as participants should be rewarded for their contribution to the public good and involved in the profits of the research [18].

A study of the impact of rewards on a patient's willingness to participate in a clinical trial found that a high payment motivated him/her to participate in the study, but there was no evidence that the payment rates commonly used was unreasonable or unfair incentives [19]. During the study of the impact on the motivation of healthy volunteers, residents of European countries, it was found that: the financial motive was the main for $53.3 \%$ of them, $27.8 \%$ indicated that the motive for their participation was the desire to contribute to pharmaceutical and medical science; for $12.7 \%$ it was a social responsibility, for $6.2 \%$ it was the opportunity to get a quality free modern examination [20, p. 32].

Payment for clinical trial participation as coercion is highly rare, as it requires a certain threat of harm to life, health or loss of property. Relevant risks should be assessed during the approval of the test report, and their acceptability must be approved by the competent authorities [13, p. 185].

For example, the US Food and Drug Administration (FDA) has defined guidelines for evaluating these payments, including payment should be made during the trial and not depend on the subject's participation until it is complete; payment that encourages continued participation in the trial is acceptable but should be a small fraction of the total. In 2014, the UK Department of Health (HRA) issued a Guide to Payments and Incentives in Clinical Trials, which provided ethics committees with guidelines for assessing the acceptability of financial incentives, such as determining the proportionality of burden payments to research (in particular, the number of required hospital visits, medical procedures, keeping certain diaries, filling out questionnaires) [13, p. 187-188].

As a result of the study, two models of contractual regulation of organizational and legal relations between the subjects involved in the clinical trial were identified. The first model is more convenient for the sponsor, as he usually concludes a contract through the CRO for a clinical trial with a hospital, which itself involves co-contractors (subcontractors), concluding contracts with them, retaining responsibility for the contract with the sponsor. This model is the most common in world practice and in some countries it is the only one acceptable. The second model is common in some post-Soviet countries and is more complicated for the sponsor, as it requires the making of a contract with a hospital for a clinical trial, as well as contracts for additional work and services with other entities involved in such a trial (members of the research group, research coordinator, HMEI, SI, other medical institutions that will provide laboratory and diagnostic services). The organizational and legal relations that arise in the case of reimbursement of expenses by the sponsor and making payments to the subject of the trial are also considered. The results of the study can be used in further research of legal relations in the field of clinical trials, as well as law enforcement practice of their contractual regulation and in improving of the current legislation. 


\section{CONCLUSIONS}

The proper organization of relations between different participants in clinical trials is the key to their clear and timely implementation. Such relationships will be governed by agreements between the sponsor and other subjects involved in the clinical trial. The participation of CRO and SMO in such legal relations is considered traditional.

The analysis of the regulatory framework and law enforcement practice allowed to identify models of linear and parallel organizational and legal relations between the subjects involved in the clinical trial, which affects their contractual registration.

The first is the most common model, which is that the sponsor (CRO) orders a clinical trial in a hospital, and the latter, if necessary, can involve other subjects to perform the contract.

The second model is characterized by the making of sponsorship (CRO) contracts with the hospital in which the PCT is defined, and also with the researcher, co-researchers, test coordinator, institutions involved in laboratory and (or) diagnostic tests that cannot be conducted in the hospital. In this case, the second group of agreements is concluded by the sponsor (CRO), mainly with subjects that are both employees of the hospital (or HMEI or SI involved into the trial by the sponsor) and within their working hours perform the sponsor's agreement with the hospital, and in free from work in the hospital time perform their own contracts with the sponsor.

The organization of a clinical trial in the second model may be accompanied by a set of agreements: 1) for a clinical trial: between the sponsor (CRO) and the hospital or between the sponsor (CRO), hospital and HMEI and (or) SI, if the latter are involved in the clinical trial on the basis of the hospital; 2) provision of additional services and (or) performance of work related to clinical trials between the sponsor (CRO) and the researcher and (or) other subjects involved in the clinical trial (in particular, the trial coordinator); 3) on cooperation between the hospital and HMEI or SI, if their employee is involved in the clinical trial as a researcher; 4) cooperation between the hospital and the researcher, other entities involved in the clinical trial, with which the sponsor (CRO) has entered into a contract for the provision of services and (or) work related to the trial; 5) on the provision of laboratory or diagnostic services between the sponsor (CRO) and specialized institutions (if they cannot be provided by the hospital where the PCT is defined).

The complexity of organizational and legal relations in the second model determines the need for an attentive attitude to the subject and terms of contracts, which should clearly delineate the functions of all persons involved in the clinical trial.

A sponsor (CRO) or hospital may engage SMO on a contractual basis to perform work (services) related to a clinical trial. If the sponsor (CRO) orders from the vendor services to organize the payment of the subject of the study, a contract may be concluded between this vendor and such a subject to regulate the procedure and conditions of the payment mentioned. This agreement may not restrict the latter's right to refuse to take part in the trial.

\section{REFERENCES}

1. FDA Guidance on Conduct of Clinical Trials of Medical Products during COVID-19 Public Health Emergency of July 2, 2020. Available from: https:// www.fda.gov/media/136238/download?fbclid=IwAR2jHwm5ytA-2a3i8Z7 U2AFhpqqD3Cyy6ozSDAtn5pv7PBSgP6MkDNDLZ-g. [reviewed 2020.07.10].

2. Monitoring processes to R\&D. World Health Organization. 2020. Available from: https://www.who.int/research-observatory/ monitoring/processes/clinical_trials_1/en/[reviewed 2020.08.07].

3. Flear M.L. The EU Clinical Trials Regulation: key priorities, purposes and aims and the implications for public health. Journal of Medical Ethics 2016;42:192-198. doi: 10.1136/medethics-2015-103258.

4. Toulouse E, Masseguin C, Lafont B, Harbonn A, A Roberts J, Granier S, Dupeyron A, Bazin JE, French legal approach to clinical research, Anaesthesia Critical Care and Pain Medicine 2018, doi:10.1016/j.accpm.2018.10.013

5. Jimenez $M$, Ferrandiz $A$, Urtasun J. New clinical trials regulation in Spain: analysis of royal decree 1090/2015. Clin Transl Oncol. 2017; 19:291-300. Available from: https://link.springer.com/content/ pdf/10.1007/s12094-016-1550-9.pdf. [reviewed 2020.07.17].

6. Guideline for good clinical practice E6(R2) of June 11, 2015. European Medicines Agency. 2015. Available from: https://www.ema.europa.eu/ en/documents/scientific-guideline/guideline-good-clinical-practicee6r2-4-step-2b_en.pdf. [reviewed 2020.08.07].

7. Melihov 0. Klinicheskie issledovaniya [Clinical trial]. Moskva: Atmosfera, 2013: 200 p. (Ru).

8. Thompson M, Hurley P, Faller B. Challenges With Research Contract Negotiations in Community-Based Cancer Research. Journal of Oncology Practice. 2016; 12(6): 626-632. doi: 10.1200 / JOP.2016.010975.

9. Lurye D. Cyvilno-pravove regulyuvannya provedennya klinichnyx doslidzhen [Civil law regulation of clinical trial conduction]/The thesis for the degree of candidate of legal sciences. 2019. -243 p. Available from: http://idpnan.org.ua/files/2019/lur_e-d.a.-tsivilno-pravoveregulyuvannya-provedennya-klinichnih-doslidjen-_d_.pdf[reviewed 2020.07.07] (Ua).

10. Ob utverzhdenii Pravil nadlezhaschey klinicheskoy praktiki Evraziyskogo ekonomicheskogo soyuza: reshenie Soveta Evraziyskoy ekonomicheskoy komissii [On approval of the Rules of Good Clinical Practice of the Eurasian Economic Union: Decision of the Council of the Eurasian Economic Commission] of November 3, 2016.- № 79. Available from: http://docs.cntd.ru/document/456026110 [reviewed 2020.07.07] (Ru).

11. Nadlezhaschaya klinicheskaya praktika: Natsionalnyiy standart Rossiyskoy Federatsii [Good clinical practice: National standard of the Russian Federation] of September 27, 2005.- № 232. Available from: http://acto-russia.org/index.php?option=com content\&task=view\&id=17 [reviewed 2020.08.07] (Ru).

12. Pro zatverdzhennia Poriadku provedennia klinichnykh vyprobuvan likarskykh zasobiv ta ekspertyzy materialiv klinichnykh vyprobuvan i Typovoho polozhennia pro komisii z pytan etyky: Nakaz Ministerstva okhorony zdorovia Ukrainy [0n Approval of the Procedure for Clinical Trials of Medicinal Products and Expertise of the Materials of Clinical Trials and Model Regulations on Ethics Commissions: Order of the Ministry of Health of Ukraine] of September 23, 2009.- №690. Available from: https://zakon. rada.gov.ua/laws/show/z1010-09 [reviewed 2020.08.10] (Ua).

13. Lurye D. Pravove regulyuvannya nadannya finansovyx vyplat doslidzhuvanym za uchast u klinichnyx vyprobuvannyax [Legal Regulation of Financial Payments Granting to Subjects for Participation in Clinical Trials . Journal of the National Academy of Legal Sciences of Ukraine. 2017; 3 (90): 182-192. Available from: http://visnyk.kh.ua/web/uploads/ pdf/323242422-182-192.pdf [reviewed 2020.08.10] (Ua). 
14. Regulation (EU) № 536/2014 of the European Parliament and of the Council of April 16, 2014. Available from: http://pharmadvisor.ru/ documents/ss3680/ss3680.html. [reviewed 2020.08.07].

15. Lawrence M. Friedman. Fundamentals of Clinical Trials. 4th ed. New York: Springer. 2010. $464 \mathrm{p}$.

16. Organizatsionnyie aspektyi provedeniya klinicheskih issledovaniy [Organizational aspects of the clinical trial]. Moskva: Gruppa «Remedium», 2017. 128 p. (Ru).

17. Shhodo zaluchennya SMO (SITE MANAGEMENT ORGANIZATIONS) do provedennya klinichnyx vy'probuvan' [0n involving SMO (Site Management Organizations) in conducting clinical trials]. State Expert Center of the Ministry of Health of Ukraine. 2018. Available from: https://dec.gov.ua/announcement/shhodo-zaluchennya-smo-sitemanagement-organizations-do-provedennya-klinichnyh-vyprobuvan [reviewed 2020.08.07] (Ua).

18. Wendler D., Rackoff J., Emanuel E. The ethics of paying for children's participation in research. Journal of Pediatrics. 2002; 141(2): 166-171. doi:10.1067 / mpd.2002.124381.

19. Halpern S., Karlawish J., Casarett D. et al. Empirical assessment of whether moderate payments are undue or unjust inducements for participation in clinical trials. Arch Intern Med, 2004; 164(7): 801-803. doi: 10.1001 / archinte.164.7.801.

20. Dobrova V. Analiz motyviv uchasti paciyentiv i zdorovyx dobrovolciv u klinichnyx vyprobuvannyax [Analysis of patients and healthy volunteers motivation for involving into clinical trials]. Management, Economics and Quality Assurance in Pharmacy. 2014.- №5.-PP. 28-34. Available from: https://dspace.nuph.edu.ua/bitstream/123456789/5446/1/ Pages from UEC_5_20141-5.pdf [reviewed 2020.08.07] (Ua).

\section{ORCID and contributionship:}

Olena I. Antoniuk: 0000-0003-1825-3981 A, B, D, E, F

Yuliia M. Pavliuchenko: 0000-0003-1504-8384 B, D, E, F

Ivan I. Vyshnyvetskyy: 0000-0001-7228-3052 ${ }^{B, D, E, F}$

\section{Conflict of interest:}

The Authors declare no conflict of interest.

\author{
CORRESPONDING AUTHOR \\ Olena I. Antoniuk \\ Supreme Cour, Kyiv, Ukraine \\ tel: +380502798954 \\ e-mail: e.antonuk@ukr.net
}

Received: 30.08 .2020

Accepted: 30.11 .2020

A - Work concept and design, B - Data collection and analysis, C - Responsibility for statistical analysis,

D - Writing the article, $\mathbf{E}$ - Critical review, $\mathbf{F}$ - Final approval of the article 